\title{
Virtual R\&D Project Teams: From E-Leadership To Performance
}

Dominique Bonet Fernandez, IPAG Business School, IPAG LAB, CRET-LOG, Aix-Marseille Université, France

Nabila Jawadi, IPAG Business School, IPAG LAB, Paris, France

\begin{abstract}
Recent research on virtual teams highlights the importance of high quality relationships to achieve high team performance. For research and development (R\&D) virtual project teams, relationships characterized by cooperation and trust are expected to enhance creativity and innovation among team members. The purpose of this paper is to identify variables enabling high quality relationship building in virtual $R \& D$ teams and to analyze their influence on team performance. To this end, this study examines the effects of leadership, work organization and communication practices on the quality of the relationship between team members. The theoretical developments are illustrated through a case study of a car development project in a leading French car-making firm, PSA. Our findings show that dynamic and positive leadership plays an important role in enhancing relationships between team members. The results also highlight the importance of synchronous meetings and frequent and regular interaction to build cooperative and trusty relationships leading to high performance.
\end{abstract}

Keywords: Virtual R\&D Project Teams; Performance; E-Leadership; Car Industry

\section{INTRODUCTION}

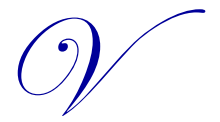

irtual teams offer an interesting means to organize work for organizations wishing to leverage scarce resources and to reach the skills required, regardless of geographic and temporal limitations. They are composed of geographically and organizationally dispersed individuals who use information and communication technologies (ICT) to accomplish work activities (Townsend et al., 1998: p. 18). Although early definitions of virtual teams have emphasized their temporary nature meaning that the team is dissolved with the achievement of the project activities, recent researches note that more permanent virtual teams are increasingly used to perform long-term work or renewal projects (Townsend et al., 1998; Lipnack and Stamps, 2000; Bell and Kozlowski, 2002; Lee-Kelly and Sankey, 2007). This can be the case of multi-site firms whose members collaborate on common project via ICT despite the geographical dispersion.

One of the fields most concerned by the virtualization of its activities is research and development (R\&D). Two main reasons explain this trend. On the one hand, like knowledge management work, R\&D activities can be performed without the collocation of team members, who can interact, exchange information and brainstorm through ICT. At the same time, the development of multi-site firms and international partnerships also contributes to the growing use of virtual R\&D teams (Howells, 2008). On a more general level, firms using virtual teams aim to enhance their performance by reaching skilled individuals, and reducing their transaction costs by cutting down on travelling and transport costs (Leung, 2010).

Yet, while this form of work organization holds considerable appeal, a number of challenges affecting performance have also been identified. In particular, virtual teams have been linked to increased levels of interpersonal friction (Hinds and Bailey, 2003; Järvenpää and Leidner, 1999; Maruping and Agarwal, 2004). Virtual R\&D project teams are particularly concerned by challenges of relationship management as high quality relationships are expected to enhance creativity and innovation. Consequently, the interest of R\&D managers shifts from the optimization of technical processes and flows to relationship management aiming to build high quality relationships that are in turn expected to have a positive influence on team performance (Bidault and Castello, 2009; Chiesa et al., 2009; Dayan et al., 2009; Ale Ebrahim et al., 2011; Liu et al., 2011). 
However, as noted by Kratzer et al., (2008), little is known about how to build high quality relationships in virtual R\&D project teams. The characteristics of this form of work organization can hinder relationship development and render their 'traditional' management practices ineffective. Heavy reliance on ICT, the distance separating team members, cultural differences, and lack of information about team members are just some of the factors that can inhibit the development of high quality relationships characterized by trust and cooperation in such teams. Our work aims to investigate the following research questions:

- What are the mechanisms facilitating the development of high quality relationships in virtual R\&D project teams?

What are the effects of high quality relationships on team performance?

We note here that high quality relationship in a team are characterized by trust, cooperation, collaboration, mutuality, respect, etc. (for further details, see work on Leader-Member exchange theory) (Erdogan and Liden, 2006; Liden et al., 2000; Uhl-Bien, 2006). High quality relationships lead to positive outcomes and are built through managerial practices and team processes. In this research, we investigate the influence of leadership, work organization and communication practices on high quality relationship-building in virtual R\&D project teams. These mechanisms have been highlighted by previous studies as key relationship and performance management factors in virtual teams (Beranek, 2000; Larsen and McInerney, 2002; Piccoli and Yves, 2003; Potter and Balthazard, 2002; Sudweeks and Simoff, 2005).

Section 2 presents the links between the principal concepts of the research namely: virtual R\&D teams' performance, the quality of the relationships between team members, leadership, work organization and communication practices. We then present a case study of a virtual R\&D team at a leading French carmakers' firm, PSA. The method adopted to collect and analyze the data is described in section 3 and followed by the presentation of the case study in section 4. Section 5 discusses our results and presents their contributions to virtual R\&D project teams' management and literature. In the concluding section, we summarize our main findings, and point to some of the limitations of our study as well as ways to address them.

\section{THEORETICAL BACKGROUND}

Four theoretical fields were mobilized: Relationship management in R\&D teams, leadership, work organization and communications practices.

\section{Relationship Management and Performance in Virtual R\&D Project Teams}

Team performance expresses the results of the collective work done by team members as well as their behaviours and attitudes. It is defined as "group-produced outputs and the consequences a group has on its members" (Piccoli et al. 2004: p. 362). For Cohen and Bailey (1997), performance in collocated teams (composed of members working in the same building) is assessed through work performance, members' attitudes and members' behaviours. With regard to virtual teams, a recent meta-analysis by Lin et al. (2008) found that performance is usually measured through work performance and satisfaction, which constitutes an attitude measure according to Cohen and Bailey (1997).

Work performance is defined as "the extent to which the group's output meets the required standards or measures" (Lin et al. 2008: p. 1033). It can be assessed through output quality (Aubert and Kelsey 2003, Furumo and Pearson 2006, Paul et al. 2004), respect for deadlines and task achievement processes (Lurey and Raisinghani 2001; Maznevski and Chudoba 2000; Montoya-Weiss et al., 2001), efficiency, profit, innovation, creativity and value creation (Furumo and Pearson, 2006; Gibson and Gibbs 2006; Kratzer et al., 2006; Paul et al., 2004).

Performance assessment through members' attitudes is expressed through their satisfaction with output quality and team processes, agreement with decisions, and individual participation in work achievement (Cohen and Bailey, 1997; Lin et al., 2008; Montoya-Weiss et al., 2001). Performance of members' behaviours is assessed through motivation and commitment to the team. According to Geister et al., (2006), teams whose members develop high levels of motivation and commitment are expected to demonstrate strong cohesion and group identity. As a 
result, the members of these teams build cooperative and trusting relationships and achieve effective team processes and high quality output (Geister et al., 2006).

High quality relationships have been identified as a key factor in enhanced team performance. Several studies have underscored the contribution of trust, cooperation, collaboration and cohesion to team performance (Berson and Linton, 2005; Bidault and Castello, 2009; Dayan et al., 2009; Liu et al, 2011). For R\&D teams, trust has been positively linked to creativity and innovativeness (Dayan et al., 2009). Bidault and Castello (2009) argue that in the case of inter-firm partnerships, formal control mechanisms are not sufficient to achieve high performance. Their empirical study suggests that a higher level of trust between the partners induces a higher level of investment in the partnership, leading to enhanced performance. Liu et al. (2011) show that high quality exchanges in R\&D project teams contribute to enhancing team performance and increasing its members' commitment to the team and their intention to share knowledge. Berson and Linton (2005) found that a positive work climate increases both job satisfaction and overall satisfaction in the face-to-face $R \& D$ teams they observed.

Findings from the studies mentioned above provide evidence that high quality relationships play an important role in enhancing the performance of collocated R\&D project teams. However, the situation is not the same in virtual $\mathrm{R} \& \mathrm{D}$ teams. The characteristics of the virtual context raise questions about how relationships are managed. Indeed, relationship building requires physical proximity, mutual exchange of information (Handy, 1995), time, a shared social context, common values and similar cultures (Meyerson et. al., 1996). However, these conditions are not always met in the context of virtual R\&D project teams. Members' dispersion, absence of physical proximity and a shared social context, the temporary nature, and electronic interactions all hinder the development of a good relationship between team members (Handy, 1995; Townsend and al., 1998).

In this regard, recent studies on virtual teams have shown that relationships develop more from task-related than socially-oriented activities (Cascio and Shurygailo, 2003; Iacono and Weisband, 1997; Johnson et al., 2002; Yoo and Alavi, 2004). Their development relies more on actions related to activity planning and achievement, respect for deadlines and task distribution than on social communications and interactions. Järvenpää et al. (1998) identified strategies and behaviors facilitating high quality (trusting and cooperative) relationship building in virtual teams. These include the style of action, the focus of dialogue, team spirit, clear goals, role division and specificity, time management, patterns of interaction, and the nature of feedback. The study also showed that teams with a leader achieved higher quality relationships than teams without a leader.

For the specific virtual context of R\&D teams, Stark and Bierly III (2009) showed that member satisfaction and overall team performance is enhanced through positive leadership based on encouragement of creativity and change, and personalized consideration for followers. Berson and Linton (2005) and Purvanova and Bono (2009) compared the transformational and transactional style of leadership in R\&D teams. Their findings indicate that the former generates stronger performance than the latter. Transformational leadership characterized by continual attention to individuals' needs and development results in a better working climate, and enhanced individual and job satisfaction.

These findings highlight three mechanisms that strongly influence relationship management in virtual R\&D teams: leadership, work organization and coordination mechanisms, and communication practices. In the following paragraphs, we explain how these three factors contribute to relationship and performance management in virtual $R \& D$ project teams.

\section{Leadership and E-Leadership}

"Leadership is a process whereby an individual influences a group of individuals to achieve a common goal" (Northouse, 2001: p.3). For Crozier and Friedberg (1977), expertise, control over the relationship with the environment, communication, and the use of procedures and processes to structure the organization constitute the bases of dynamic leadership. According to Shipley and Egan (1992), leaders have to adopt a partnership mode and use persuasion to successfully manage the other team members. It is in the leader's interest to develop a platform of confidence, harmony and cooperation, resulting in performance delivery. In order to create this platform, abundant 
communication, personal interaction, respect, honesty, consensus, recognition of mutual interest, and behavioral coordination are needed, (Bonet and Poirel, 2009).

However, team virtuality involves considerable changes to the characteristics and exercise of team leadership (henceforth called e-leadership). E-leadership is defined as a socially influencing process for producing a change in attitudes, feelings, thinking, behavior, and/or performance with individuals, and/or groups (Avolio and Kahaï, 2003; Avolio et al., 2001). However, it becomes mediated by information and communication technologies as they are the main means of interaction in the virtual context. E-leadership styles and functions have to adapt and integrate virtuality in order to be effective and to ensure the success and performance of virtual teams. As a result, eleaders have to deal with challenging issues generated by distorted communication processes, member diversity, technical problems and, in some cases, time pressure (Kayworth and Leidner, 2001/2002). All of these factors need to be taken into consideration when formulating strategies for building and reinforcing relationship between team members.

Consistent with behavioral complexity theory of leadership in collocated work teams (Denison et al., 1995), leaders need to develop a portfolio of complementary and, at the same time, paradoxical roles and behaviors to manage their subordinates and to be effective. Applying behavioral complexity theory to virtual teams, Kayworth and Leidner (2001-2002) and Yoo and Alavi (2004) show that e-leaders are most concerned with three main areas of team management: task achievement, individual team members' needs and team cohesion, which all influence relationship quality either directly or indirectly.

First, as relationship development in virtual teams is related more to 'doing' than to 'feeling' (Meyerson et al., 1996), it is influenced by interactions that focus on activity planning and goal achievement. Hence, e-leaders need to schedule work, set deadlines and control workflows clearly in order for them to be respected. They also have to establish coordination mechanisms that facilitate information sharing and work exchanges between team members as "the issue of coordination becomes more complex when virtual teams interact asynchronously" (Paul et al., 2004: p. 317).

This implies that e-leaders need to pay particular attention to technical issues. Indeed, accessibility and the effective use of information and communication technologies are key conditions for ensuring the proper achievement of work as they are the exclusive means of communication in the absence of face-to-face interaction. In addition, e-leaders have to consider differences in time zones when preparing activities and organizing virtual meetings. Attendance of all team members or a majority of them is essential to resolving work-related issues, explaining and clarifying task schedules, and ensuring that there are no 'free riders'. In this way, e-leaders are able to uphold a dynamic, positive and optimistic team spirit that helps to establish trust and cooperation within the team (Järvenpää et al., 1998).

Second, e-leaders are also concerned with the needs of individual team members. Indeed, virtual team members may feel isolated as most interaction occurs in electronic spaces (Sarker and Sahay, 2004). They may neither see nor know one another given their physical separation. This can create a feeling of isolation, inhibit their commitment to the team and their goals, and damage the potential collective social context.

E-leaders need to encourage team members to exchange social information to help them to get to know each other better and to assess their behaviors and build shared norms. There are two main ways to do this. On the one hand, they can organize one face-to-face meeting at least at the onset of the project when the team members would be introduced to one another. This would also facilitate future electronic interactions and provide more visibility and collective awareness in the team (Daassi et al., 2006; Zigurs, 2003). On the other hand, when it is impossible to hold face-to-face meetings, e-leaders may use team-building exercises before the project effectively begins, which "should not only reveal information about the members, but also create a team identity" (Järvenpää et al., 1998: p. 3). Team-building exercises can also be useful when e-leaders face time pressure in short lifecycle teams, which is the case of virtual $R \& D$ project teams. In this context, leaders have to act rapidly to establish effective communication patterns and trusting relationships. 
Third, leaders of virtual R\&D teams are concerned with team cohesion management, including cultural diversity management and conflict resolution (Lurey and Raisinghani, 2001). As virtual teams are spread across organizational, functional and professional boundaries, they may include members from different cultures who speak different languages and have different perceptions and referents. E-leaders have to deal with this diversity and find a common area of understanding, establishing a set of collective and accepted norms to guide behaviors. They also need to intervene at the appropriate moment to resolve any misunderstandings related to language barriers or conflicting perceptions.

\section{Work Organization and Coordination Mechanisms}

Work organization refers to different ways of structuring work activities in virtual R\&D teams and facilitating its execution. It also includes coordination mechanisms and procedures. Gassmann and von Zedtwitz (2003) identify four main ways to structure work in virtual R\&D teams. They classify these structures according to an increasing level of decentralization. The first category, called decentralized self-coordination, includes selfdirected teams with no central manager. Formal coordination and control mechanisms are weak and are mainly based on "modern information and communication technologies such as internet, shared databases, groupware as well as telephone and fax" (Gassmann and von Zedtwitz, 2003: p. 246).

The second way to organize virtual $R \& D$ activities is to designate a system integrator and project coordinator to be in charge of creating interfaces between the different actors in the team, defining work packages and coordinating decentralized R\&D activities (Gassmann and von Zedtwitz, 2003: p. 248). This form of work organization is better suited to temporary R\&D teams with short lifespans.

Communication mechanisms used for work accomplishment are heavily based on ICT. However, Gassmann and von Zedtwitz (2003) highlight the importance of initial face-to-face meetings between team members and subsequent regular contact. Indeed, a face-to-face meeting at the beginning of the project helps team members to build up initial mutual knowledge in order to assess one another's behaviors. Mutuality is a key determinant in enhancing relationship development and building trust and collaboration.

The third category described by Gassmann and von Zedtwitz (2003) is based on a core team to coordinate and supervise the work of collocated R\&D teams. This structure is suited to firms using highly interdependent project teams and wishing to develop better control coordination mechanisms. However, as collocation of all the teams is impossible to develop, such firms form "a core team" made up of a project manager, a team leader and internal business customers. Coordination mechanisms include collaborative tools such as intranet, internet, groupware and videoconferencing.

The last structure of virtual $R \& D$ team is based on centralized venture teams. A core team is constituted to re-collocate in the same building members who were dispersed. In this case the proximity of the centralized venture team members is considered as a key determinant of the project sucess. The core team is responsible for planning and execution of all activities of an R\&D project. The project manager, who is also the manager of the venture team benefits from a high level of autonomy in resources allocation and coordination of all sites of the project. According to Gassmann and von Zedtwitz (2003), centralized venture teams are best suited to crucially important strategic innovation projects. In this case, most communication occurs in face-to-face fashion and team members use technological tools specific to the workflow.

Whatever the structure of virtual R\&D work processes, relationship building is based on setting goals, and clarifying the projected work and contribution of each member to the final result through clear task repartition (who does what). Establishing schedules and deadlines and respecting them is also a key factor in high quality relationship building. These actions help to reduce the uncertainty and ambiguity associated with the virtual context generated by a lack of information about team members and their behaviors (Maznevski and Chudoba, 2000; Montoya-Weiss et al., 2001). 


\section{Communication Practices}

The effects of electronic communication on group dynamics and performance have informed several studies (Poltrok and Engelbeck, 1999; Sarker and Sahay, 2004). The findings of previous studies on virtual teams highlight the importance of regular, frequent and task-focused interactions, and the combination of different communication tools to develop high quality relationships and ensure performance (Geister et al., 2006; Potter and Balthazard, 2002).

Iacono and Weisband (1997) studied the effects of the nature of communication on the development of trusting team relationships. The results show that work-oriented messages characterize interactions that lead to a high degree of trust in teams, unlike socially-focused messages. The authors also highlight the importance of providing virtual team members with appropriate communication tools, and facilitating access to these tools. In addition, high performing teams tend to draw up communication norms for planning and organizing the virtual work.

Järvenpää et al. (1998) and Järvenpää and Leidner (1999) noted the importance of interaction frequency and fast feedback in building high quality relationships between virtual team members. Moreover, Potter and Balthazard (2002) found that interaction style is strongly correlated with the relationship's development and the team performance. They noted that a constructive style of interaction (as opposed to an aggressive or passive style) helps virtual team members to build trusting relationships and achieve better performance.

The initial interaction between members has also been identified as an important factor in the development of virtual team relationships (Järvenpää et al., 1998; Meyerson et al., 1996). It forms the basis of first impressions and stereotypes, identified as the psychological mechanisms that virtual team members use to form judgments about each other's behaviors and which come into play early on in the relationship when members know little about one another (Walter, 1995).

The previous developments enabled us to show that high quality relationships positively influence virtual $\mathrm{R} \& \mathrm{D}$ project team performance. Building trust, cooperation and collaboration between team members is achieved, among other things, through a dynamic and positive style of leadership, effective work organization and coordination mechanisms, and frequent and constructive interactions. Theoretical backgrounds from the exemplary ICT industry have provided a set of relevant variables that enlightens the study of R\&D performance in our specific empirical field: the car industry. To our knowledge, this innovative framework is the best adapted to discuss our research question.

\section{METHODOLOGY}

Given the exploratory nature of our work, we adopted the case study method, considered as a useful means of understanding complex and new phenomenon (Eisenhart, 1989). While the issue of relationship management has been extensively studied in virtual teams, this is not true for virtual R\&D project teams. We therefore felt that the case study would be the most suitable method for analyzing and understanding how high quality relationships are built, and their impact on team performance.

The case we describe is a car development project called T13 that brought together a French carmaker PSA, two European subcontractors located in Germany (EDAG and PORSCHE), and the client located in an emerging middle-eastern country (called in what follows EC) ${ }^{1}$. In addition to the challenges associated with geographical and temporal dispersion, the configuration of this team generates a high cultural diversity which derives from diversity in national, professional and personal culture of team members. In the following paragraphs, we present the T13 project and how the data was gathered and analyzed.

\footnotetext{
${ }^{1}$ For confidentiality reasons, we use acronyms to designate this actor participating in the T13 project who prefer to remain anonymous. 


\section{The T13 Project}

PSA is a leading French carmaker. The T13 project consists of a car development for a middle-eastern country, destined for the Middle East and Maghreb (North Africa) markets. Consistent with the classification of Gassman and von Zedtwitz (2003), a core team was constituted to facilitate the coordination of the project activities. The team was composed of 7 members: 4 french engineers from PSA, two German subcontractors and the product and quality vice president of EC. The project manager, who supervises the whole project, was one of the 4 engineers of PSA. He also was the core team manager and was considered as the leader of the project. The EC provided financial support for the project and fixed performance criteria for PSA. Three conditions were set out: a two-year deadline for the project, respect for international quality standards and full funding from EC. PSA attributed the requisite human resources to the project and established a partnership with the German subcontractors. Although all members of the core team were not collocated, information exchanges between them were frequent and intense as we will explain later.

\section{Data Collection and Analysis}

Data were collected right after the completion of the project between March and April 2009, updated in october 2013, through interviews with the different partners available at that time, in the T13 project. Interviews were conducted through face-to-face, telephone and email exchanges. Three in-depth face-to-face interviews were conducted with the PSA project manager at PSA headquarters in Paris. For the two subcontractors (EDAG and PORSCHE engineering managers), the telephone interviews from Germany lasted 45 minutes each. The representive of EC (Product and Quality Vice-president) was contacted through 2 email exchanges. An interview protocol was developed to this end. It included 4 themes: description of the firm, the strengths of the project work methodology, its weaknesses (in these two themes we addressed the quality of the relationships) and the extent to which the performance targets were met. In line with Miles and Huberman (1994), all of the interviews were recorded, transcribed and subjected to a thematic content analysis linked to our research questions. The data was thus structured into three categories: leadership and its characteristics, work organization, and communication practices. The information collected enabled us to identify and assess the quality of the team relationships and the team performance.

\section{THE CASE: AN INTERNATIONAL VIRTUAL R\&D TEAM}

According to our interviewees and the different information collected on how the project was conducted, the T13 project is considered as a successful project that met the fixed performance criteria. The car was delivered on time and it respected the quality norms and the planned budget. In addition, all the partners were satisfied with both the output and the relationship quality. "I can say now, on completion of the project, that I was not confident at the beginning. Considering the heterogeneity of the project team, I was $98 \%$ sure that we would fail... but actually it's a total success," PORSCHE engineering manager.

\section{The T13: Work Organization}

The T13 project comprised 3 complementary activities: organic activities related to the manufacturing of a part or a component of the vehicle (a dashboard may be developed independently from the rest of the vehicle); synthesis activities aiming to ensure the coherence of the vehicle parts. A "synthesis activities" team was created to this end (i.e.: acoustic, driving and handling characteristics...); industrial activities that made up the assembly process were organized into four classic stages: stamping (forming units), body in white assembly process (assembly of parts), painting, trim part assembly process and finishes.

Every actor in the project was in charge of a set of activities. PSA supervised all the project management stages, design and industrialization, definition and validation. E.C also contributed to project management, design and vehicle synthesis, and was in charge of the industrialization of the final product (the car). EDAG had the mission of system design, and PORSCHE engineering was in charge of vehicle synthesis and tests. 
The challenge was to coordinate all the activities between the international partners within a 2-year timeframe, with high quality standards. In addition, the collaboration between the partners from different countries implied managing the cultural diversity relative to differences in perception, language, etc. In order to achieve these objectives, PSA used a classic method (the V-cycle), together with very close communication between the partners. The V-cycle development approach consists of breaking down the vehicle manufacturing process into subsets, then into parts followed by a re-composition of the parts into subsets to obtain a prototype and pre-series before the final stage of production as described in Figure 2, by the project manager. Unlike a traditional innovation-focused project, the only innovations required here were in the pursuit of international quality standards and the management of an international team. Thus, the stage of style/design was skipped as the team used an existing design in the development of the T13. This enabled the team to build on previous innovations and also to shorten the T13's timeframe. The project was split into 9 stages.

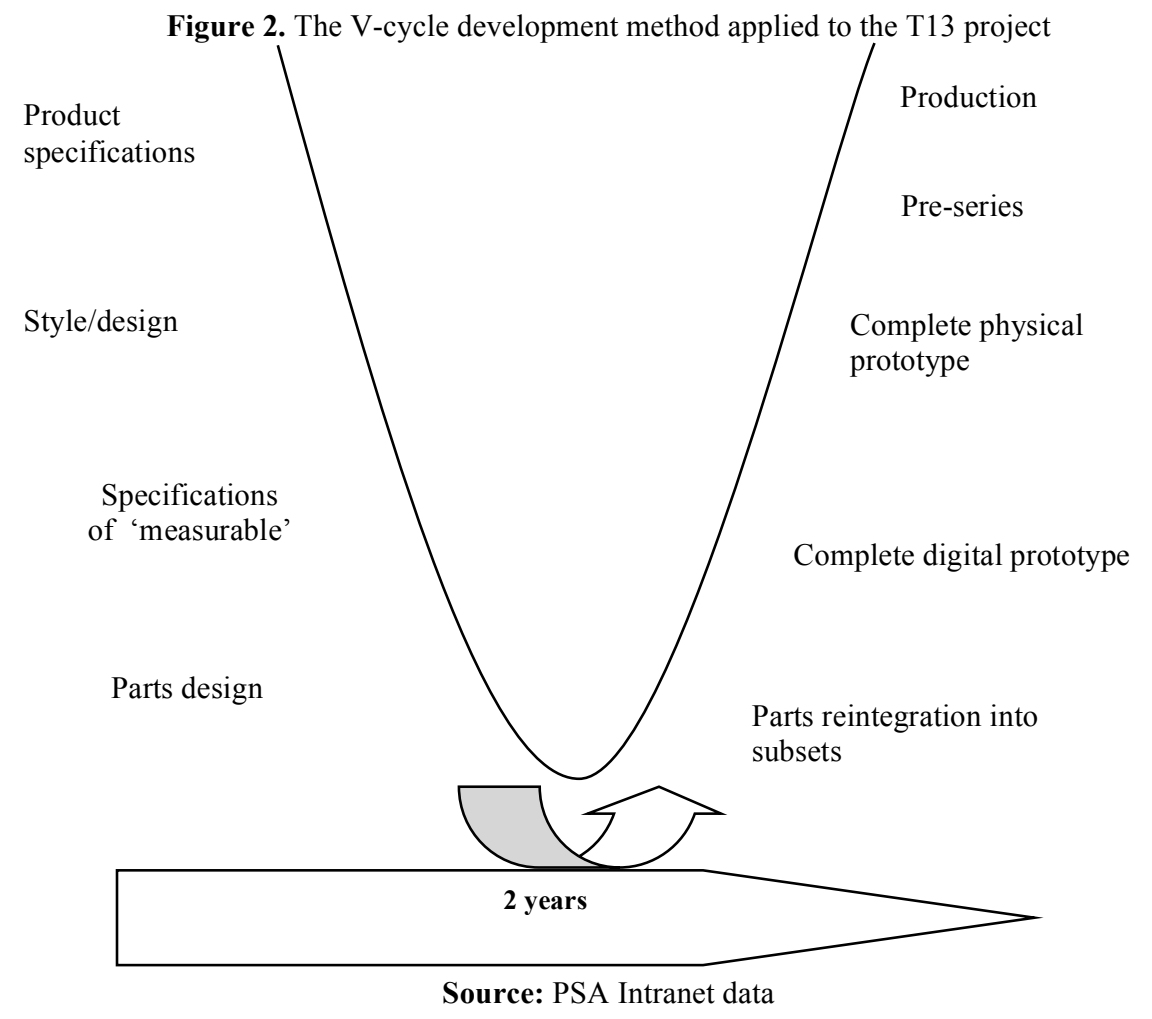

A two-day seminar was held in Germany as the project starting point. The work breakdown structure (WBS) was presented and explanations were given of the expected activities per phase (organic, synthesis and industrial) and a work group was allocated to each activity. A representative from PSA attended each of the 3 work groups involved. Each of the work groups included a leader (PSA engineer), an organic activity manager (PORSCHE engineer), a synthesis activity manager (EDAG engineer) and an industrial activity manager (EC engineer). During the presentation, each group was asked to define what needed to be done, and to give a work breakdown structure (WBS) and a detailed list of tasks (who, what, when). The project management WBS was used at the beginning of the project to define the scope, estimate costs, organize Gantt schedules and set up coordination mechanisms. The WBS of the project described by the project manager is presented in Figure 3. 
Figure 3. Work Breakdown Structure of the T13 project

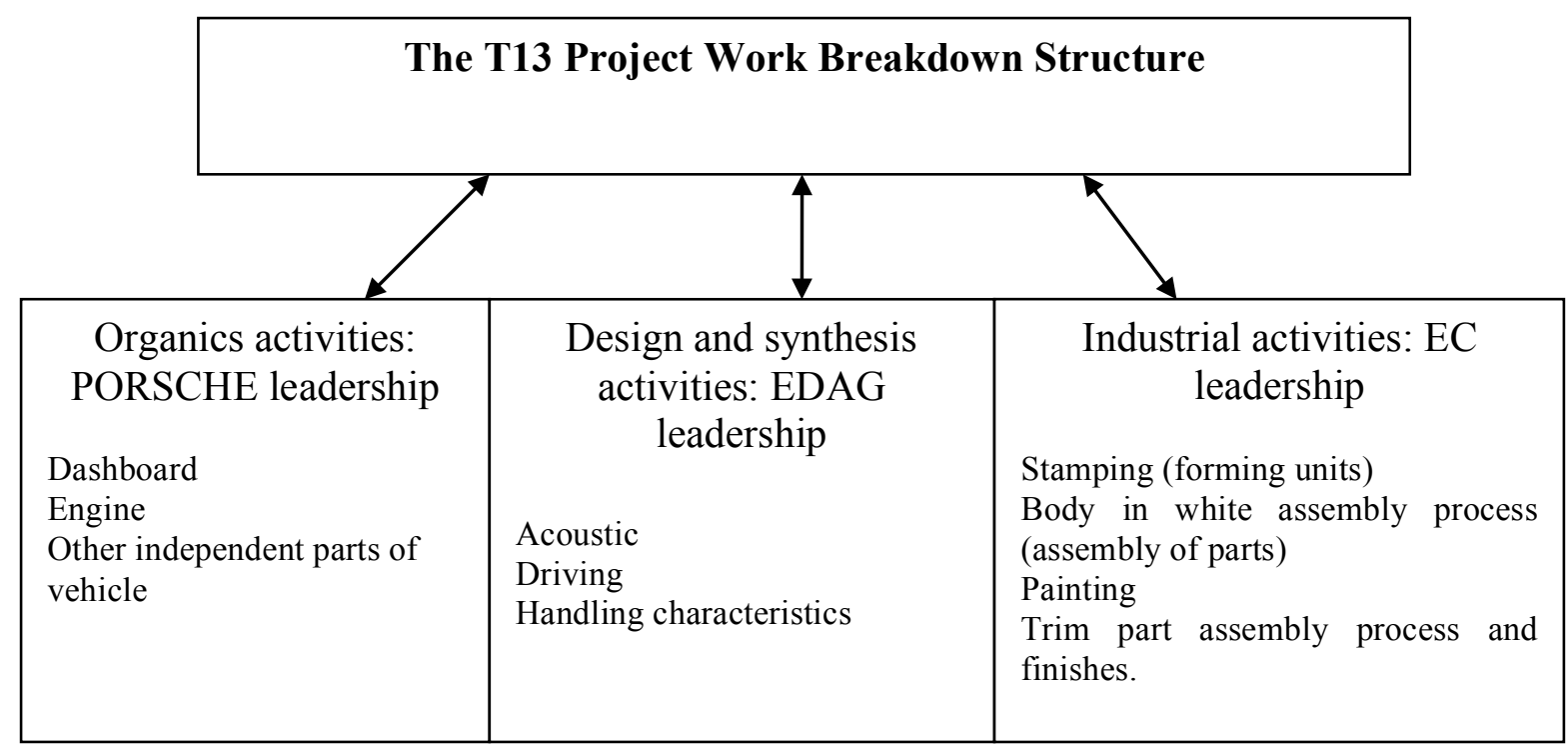

Source: PSA Intranet data

While industrial activities were supervised by the EC engineer, organic activities were performed by an engineer from PORSCHE in Germany and design and synthesis activities were handled by a EDAG engineer. In France, a team of 4 PSA French engineers, led by the project and team manager insured the coherence of the project.

\section{The T13: Positive and Dynamic Leadership}

As a leader, the project manager, as team manager, played a pivotal role in this "success story." $\mathrm{He}$ encouraged exchange of information and interaction between members in both face-to-face and electronic fashion. He organized the work, formed work groups and coordinated their activities. The project's implementation began with a team-building session to create group cohesion in a context of heavy time pressure for a short life-cycle project. The leader rapidly introduced dynamics that promoted effective communication and trust-based relationships. He reported that "the whole project relied on trust, clarity, transparency and accuracy in traceability."

The interviewees viewed the team manager's leadership as positive and dynamic. According to EC's product and quality vice president: "He was in charge of managing not only the PSA team but also, and above all, project parties to ensure the robust and integrated management of parties toward the project's objectives." The leader accomplished both task-related and socially-related activities. He was the system integrator and the project coordinator. "He was in charge of setting up multidisciplinary teams that worked interactively, building the project up through an iterative process that valued apprenticeship, and creating an information infrastructure of all the project activities, offering a common platform for all the contributions with direct and frequent dialogue between all the project partners" (Product and Quality Vice-president, EC).

The leader's effectiveness relied not only on his ability to manage relationships and communication issues, but also to effectively organize the work activities, which resulted in respect for performance criteria (deadlines and quality norms). According to EDAG's engineering manager "He managed the project in a highly professional manner in line with project knowledge management principles which were perfectly adapted to our company organization." In this sense, leadership played an important role in establishing high quality relationships in the team and, at the same time, conducting team members towards a successful and positive outcome. 


\section{T13: A Mixed Communication Process}

Despite the distance separating the different partners and team members, the emphasis was on direct and synchronous communications, even when using ICT. For this reason, a face-to-face meeting was organized in Germany at the onset of the project. According to the team manager, the initial face-to-face meeting enabled team members to get to know one another, subsequently facilitating work processes. After the presentation session, each work group had to produce its 'animation cycle', which consisted of determining the rhythm of interaction and the tools to be used to execute the work. All of the groups had to decide when and how to interact. This animation cycle consisted of a weekly teleconference for the working groups. It is very important for people to develop their own tasks together and to use a direct communication process to promote collaborative relationships. In this case, the rule was that no e-mails could be exchanged to ask questions. Rather, questions and clarifications were required in meetings. Meetings were organized as follows:

- Level 1: a weekly intra-group meeting. Once a week, an update was made of the progress in relation to the schedule, and the working groups assessed their progress. This level accounted for $90 \%$ of problem resolution. The remaining $10 \%$ was transferred to level 2 meetings.

- $\quad$ Level 2: a weekly meeting involved the project manager and work groups to discuss problematic issues at their request; e.g., the difficulty the design team had to elaborate a plan or design in line with the industrial constraints and requirements "designers must respect the specifications, EDAG had to make sure that the design propositions met the marketing requirements... For example, designers tend to elaborate low cars with big wheels. In doing so, the space from head to ceiling is too small and the driver is not comfortable. We had to find a compromise between style and comfort, between PORSCHE design and EDAG constraints..." (EDAG engineering manager). "At this point, a decision to downgrade the specification or modify the process can be taken" (PSA project manager). As the groups were autonomous, these meetings were limited and irregular. This level accounted for $10 \%$ of problem resolution.

- $\quad$ Level 3: a monthly meeting with project sponsors (EC) to present and analyze performance indicators. " $A t$ this level, only main issues are addressed: cost, investment and time decisions related to changes in the contract" (Project manager, PSA). The level 3 meeting is also designed to identify specific problems and dispatch them to level 1 and 2.

In addition to face-to-face meetings and regular teleconferencing, other tools such as Excel and WebEx were implemented for tasks lists, schedules, information on deadlines, key issue reminders, and the weekly work schedule for each group: "It's important to say what we do and to do what we say" (project manager, PSA). The main concern was always to respect the schedule through frequent and regular communication.

Workgroups also used specific software for the car's design and development. CATIA design software was used by all the workgroups, and digital models were accessible to all the partners via a collaborative web platform.

In spite of the major contribution of ICT and Catia 3D software to facilitate the work's progress and information flow in the project as a whole, the project manager declared that "nothing can replace direct and synchronous communication between people." Success was not so much a matter of innovation or collaborative tools but more of dialogue between the team members. He added in conclusion: "Direct and frequent communication was certainly the key to the successful completion of the project along with the establishment of project phases, definition of plans and required metrics to control the project, and the implementation of a gateway methodology."

\section{DISCUSSION}

Our ambition in conducting this study was to identify key actions enabling high quality relationship building in virtual R\&D project teams that lead to high team performance. We mainly focused our attention on leadership, work organization and communication practices. The case study findings provide insights into the above mentioned mechanisms that lead to trusty and collaborative relationships. 
Concerning leadership, the positive dynamic established by the T13 team manager can be explained by his ability to manage the work activities and social aspects of the way the team functioned. As not all the team members knew one another, he organized an initial face-to-face meeting where the team members were able to meet. This facilitated subsequent electronic interactions, provided greater visibility and responsiveness within the team and built up mutual knowledge and collective awareness (Daassi et al., 2006; Zigurs, 2003). This is in line with Gassmann and von Zedtwitz's (2003) recommendations regarding the importance of initial face-to-face meetings between team members and subsequent regular contact.

In addition, the team leader established coordination and work flow mechanisms both within and between groups. He encouraged regular meetings to check up on work progress, and to pinpoint and anticipate problems and ways to resolve them. In this way, control mechanisms relevant to collocated teams were substituted by trusty relationships and points that required checking with the team manager. In line with leadership behavioral complexity theory (Denison et al., 1995), the team leader developed a portfolio of complementary and, at the same time, contradictory behaviors to increase his effectiveness.

With respect to the work organization, a good balance between autonomy and control led to effective coordination mechanisms that resulted, in fine, in the deadline being respected. Indeed, the whole WBS was performed with the participation of all the partners. This phase was supervised by the team manager. After identifying the tasks of the WBS (who does what and when), each group worked autonomously. The use of a collaborative platform encouraged information sharing and facilitated work flow between the various work groups.

Regarding communication, regular meetings (both electronic between workgroups and face-to-face within groups) contributed to an increase in interaction frequency and provided the team members with rapid feedback. It also helped the team to find answers and solutions to any difficulties encountered rapidly. In this regard, the project manager stressed the importance of synchronous meetings in order to develop effective mechanisms within the team. He felt that electronic communications were insufficient, noting that "information technologies are only part of the solution," and that the success of such projects is down to a balanced combination of face-to-face and computer-mediated communication.

These findings should be taken with caution as they relate to a specific team project. Indeed, for teams with shorter lifespans, where time pressure is greater and financial resources are reduced, face-to-face meetings may be impossible to organize and members will interact exclusively through ICT. In such a case, rich media are needed to build effective coordination mechanisms, fluid communication and high quality relationships.

Our findings do allow us to formulate some research contributions, however. First our study provides useful insights into key processes in virtual $R \& D$ project teams. Leadership as well as work structure and communication are key factors in team performance. The emphasis is on leadership, considered as a central factor that influences all the other mechanisms.

Second, our study enabled us to fill a gap in the $R \& D$ literature regarding relationship building in virtual project teams and its impact on performance. Although the issue has been well covered in the general literature of virtual teams, there is little about R\&D project teams. Our study can be considered as one of the first attempts to understand the specificities of virtual $R \& D$ project teams in terms of both relationships and performance management.

At managerial level, it is important for virtual activity teams to organize regular meetings and at least one face-to-face meeting at the onset of the project. The results of our research and the different viewpoints gathered recognize that mediated communication can hinder team performance as it may fuel the ambiguity of the virtual context and limit social communications between members. 


\section{CONCLUSION}

We analyzed the role played by leadership, work organization and coordination mechanisms and communication practices in building high quality relationships. Aligned with previous findings in virtual team management literature, our research highlights the central role of the leader who organizes the teamwork and social interactions. Our main contribution is to show that ICT alone cannot ensure the optimization of exchange, but that synchronous and frequent interactions provide more fluidity to team processes and positively influence both relationship management and performance. Success is based less on innovation or collaborative tools and more on interaction and the dialogue between the team members. The findings of this exploratory study should be considered as preliminary findings that need to be extended. Our contribution requires additional and more in-depth observation to contribute to the diffusion of best practices in virtual R\&D team management.

In this regard, some limitations are important to note. On the one hand, we focused on just three mechanisms (leadership, work structure and communication). Other factors may also be important and influence relationships and team performance. For example, as virtual R\&D project teams rely heavily on ICT, their characteristics and the way it is used are likely to influence the team dynamics. Thus, teams using only one media will not have the same outcomes as teams using a combination of tools with varying levels of richness (Daft and Lengel, 1986; Daft et al., 1987) and high informational value (Kirkman and Mathieu, 2005).

On the other hand, as our results are based on only one case study, this restricts our findings and does not allow us to generalize them. It would be interesting to conduct other case studies using a different methodology such as a survey of a large population of virtual R\&D team members in order to gain further insights into the topic.

In addition, our findings should be taken with caution given the specificities of the case study. The T13 team was composed of culturally diverse members (both in terms of nationality, -French, German and from Middle East and field expertise), which is not the case for all virtual R\&D project teams. For example, projects composed of members sharing similar cultural backgrounds may not face the same challenges as more diverse teams. Similarly, teams composed of members who have worked together in the past may not have the same dynamic and way of functioning as team members working together for the first time. We believe that the team configuration needs to be taken into account when analyzing key performance factors.

Our research agenda should provide useful insights to enhance this study. We intend to explore the effects of the level of team virtuality on the outcomes of virtual R\&D project teams. Indeed, recent studies on virtual teams indicate that team outcomes and performance depend on the level of virtuality (Chudoba et al., 2005; Schweitzer and Duxbury, 2010; Kirkman and Mathieu, 2005). Findings from these studies show that virtuality (which depends on the distance between team members, the extent of their ICT use, the characteristics of media used, etc.) is inversely related to team performance, which means that a high level of virtuality leads to low performance and vice versa. Thus, we will study how virtuality influences performance.

\section{ACKNOWLEDGEMENTS}

The authors wish to express their deepest gratitude to Jean-Luc Désiré, Project director at PSA, for his precious contribution to the PSA case study.

\section{AUTHOR INFORMATION}

Dominique Bonet Fernandez is Professor at IPAG, Paris, France and affiliated to the Center of Research on Transport and Logistics (CRET-LOG) at Aix-Marseille Université, France. She holds a $\mathrm{PhD}$ in Management Science from Aix-Marseille Université.

Nabila Jawadi is Professor at IPAG Business School and affiliated to IPAG LAB, Paris, France. She holds a PhD in Management Science from Université Paris-Dauphine, France. 


\section{REFERENCES}

Ale Ebrahim, N., Abdul Rashid, S. H., Ahmed, S., and Taha, Z. (2011) The Effectiveness of Virtual R\&D Teams in SMEs: Experiences of Malaysian SMEs. Industrial Engineering and Management Systems, 10, 2, 109-114.

Aubert, B. A., and Kelsey, B. L. (2003) Further Understanding of Trust and Performance in Virtual Teams. Small Group Research, 34, 5, 575-618.

Avolio, B.J. and Kahaï, S.S. (2003) Ading the "E" to E-Leadership: How it may impact your leadership. Organizational Dynamics, 31, 4, 325-338.

Avolio, B.J., Kahaï, S.S. and Dodge, G.E. (2001) E-leadership: Implications for theory, research, and practice. Leadership Quarterly, 11, 4, 615-668.

Bell. B., and Kozlowski. S.W. (2002) A typology of virtual teams, implications for effective leadership. Group \& Organization Management, 27, 14-49.

Beranek, P.M. (2000) The impacts of relational and trust development training on virtual teams: an exploratory investigation. Proceedings of the $33^{\text {rd }}$ Hawaii International Conference on System Sciences.

Berson, Y. and Linton, J.D. (2005) An examination of the relationships between leadership style, quality, and employee satisfaction in $\mathrm{R} \& \mathrm{D}$ versus administrative environments. $R \& D$ Management, 35, 1, 51-60.

Bidault, F. and Castello, A. (2009) Trust and creativity: understanding the role of trust in creativity oriented joint developments. $R \& D$ Management, 39, 3, 259-270.

Bonet, D. and Poirel, C., (2009), Power and leadership in the supply chain: a case study, Proceedings of the $16^{\text {th }}$ International annual EurOMA Conference, June 14-17th, Göteborg, Sweden.

Cascio, W.F. and Shurygailo, S. (2003) E-leadership and virtual teams. Organizational Dynamics, 31, 4, 362-376.

Chiesa, V., Frattini, F., Lazzarotti, V. and Manzini, R. (2009), Performance measurement in R\&D: exploring the interplay between measurement objectives, dimensions of performance and contextual factors. $R \& D$ Management, 39, 5, 488-519.

Chudoba, K. M., Wynn, E., Lu, M. and Watson-Manheim, M. B. (2005) How Virtual Are We? Measuring Virtuality and Understanding its Impact in Global Organization. Information Systems Journal, 15, 4, 279-306.

Cohen, S. G., and Bailey, D. E. (1997) What Makes Teams Work: Group Effectiveness Research from the Shop Floor to the Executive Suite. Journal of Management, 23, 3, 239-290.

Crozier M. and Friedberg E. ([1977] 1992) L'acteur et le système. Les contraintes de l'action collective, Éditions du Seuil, coll. Points Essais.

Daassi, M., Jawadi, N., Favier, M., and Kalika, M. (2006) An empirical investigation of trust's impact on collective awareness development in virtual teams. International Journal of Networking and Virtual Organisation, 3, 4, 378-394.

Daft, R. L., Lengel, R. H. and Trevino, L. K. (1987) Message Equivocality, Media Selection and Manager Performance: Implication for Information Systems. MIS Quarterly, 11, 3, 355-366.

Daft, R.L. and Lengel, R.H., (1986), Organizational Information Requirements, Media Richness and Structural Design. Management Science, 32, 5, 554-571.

Dayan, M., Di Benedetto, C.A. and Colak. M. (2009) Managerial trust in new product development projects: its antecedents and consequences. $R \& D$ Management, 39, 1, 21-37.

Denison, D. R., Hooijberg, R. and Quinn. R. E. (1995) Paradox and performance: Toward a theory of behavioural complexity in managerial leadership. Organization Science, 6, 5, 524-540.

Eisenhart, K.M. (1989) Building theories from case study research. Academy of Management Review, 14, 4, 532550 .

Erdogan. B., and Liden, R.C. (2006) Collectivism as a moderator of responses to organizational justice: Implications for leader-member exchange and ingratiation. Journal of Organizational Behavior, 27, 1-17.

Furumo, K., and Pearson, M. J. (2006) An Empirical Investigation of How Trust, Cohesion, and Performance Vary in Virtual and Face-to-face Teams," Proceedings of the $39^{\text {th }}$ Hawaii International Conference on System Science.

Gassmann, O. and von Zedtwitz, M. (2003) Trends and determinants of managing virtual R\&D teams. $R \& D$ Management, 33, 3, 243-262.

Geister, S., Konradt, U., and Hertel, G. (2006) Effects of Process Feedback on Motivation, Satisfaction, and Performance in Virtual Teams. Small Group Research, 37, 5, 459-489.

Gibson, C. B., and Gibbs, J. L. (2006) Unpacking the Concept of Virtuality: The Effects of Geographic Dispersion, Electronic Dependence, Dynamic Structure, and National Diversity on Team Innovation. Administrative 
Science Quarterly, 51, 451-495.

Handy, C. (1995) Trust and virtual organization. Harvard Business Review, 73, 3, 40-50.

Hinds, P. J. and Bailey, D. E. (2003) Out of Sight, out of Sync: Understanding Conflict in Distributed Teams. Organization Science, 14, 6, 615-632.

Howells, J. (2008) New directions in R\&D: current and prospective challenges. R\&D Management, 38, 3, 241-252. Iacono, C.S. and Weisband, S. (1997) Developing trust in virtual teams. $30^{\text {th }}$ Annual Hawaii Conference on System Science.

Järvenpää, S. L. and Leidner, D. E. (1999) Communication and Trust in Global Virtual Teams. Organization Science, 10, 6, 791 .

Järvenpää, S.L., Knoll, K. and Leidner, D.E. (1998) Is There Anybody out There? Antecedents of Trust in Global Virtual Teams. Journal of Management Information Systems, 14, 4, 29-64.

Johnson, S.D., Suriya, C., Yoon, S.W., Berrett, J.V. and LaFleur, J. (2002) Team development and group processes of virtual learning teams. Computers \& Education, 39, 4, 379-393.

Kayworth, T. and Leidner, D. (2001-2002) Leadership Effectiveness in Global Virtual Teams. Journal of Management Information Systems, 18, 3, 7-40.

Kirkman, B. L. and Mathieu, J. E. (2005) The Dimensions and Antecedents of Team Virtuality. Journal of Management, 31, 5, 700-718.

Kratzer, J., Leenders, R. T. A. J., and Van Engelen, J. M. L. (2006) Managing Creative Team Performance in Virtual Environments: An Empirical Study in 44 R\&D Teams. Technovation, 26, $42-49$.

Kratzer. J, Gemunden, H.G. and Lettl, C. (2008) Balancing creativity and time efficiency in multi-team R\&D projects: the alignment of formal and informal networks. $R \& D$ Management, 38, 5, 538-549.

Larsen, K.R.T., McInerney, C.R. (2002) Preparing to work in virtual organization. Information \& Management, 39, $6,445-456$.

Lee-Kelly, L. and Sankey, T. (2008) Global virtual teams for value creation and project success: A case study. International Journal of Project Management, 26, 1, 51-62.

Leung, F. (2010) New paradigms for the future: keynote perspectives from The R\&D Management Conference 2008. R\&D Management, 40, 1, 4-9.

Liden. R.C., Wayne. S.J., and Sparrowe. R.T. (2000) An Examination of the Mediating Role of Psychological Empowerment on the Relations Between the Job, Interpersonal Relationships, and Work Outcomes. Journal of Applied Psychology, 85, 407-416.

Lin, C., Standing, G., and Liu, Y. C. (2008) A Model to Develop Effective Virtual Teams. Decision Support Systems, 45, 1031-1045.

Lipnack. J., and Stamps. J. (2000) Virtual teams. 2nd ed. New York: Wiley.

Liu, Y., Keller, R.T. and Shih, H.S. (2011) The impact of team-member exchange, differentiation, team commitment, and knowledge sharing on R\&D project team performance. $R \& D$ Management, 41, 3, 274287.

Lurey, J.S. and Raisinghani, M.S. (2001) An empirical study of the best practices in the virtual teams. Information \& Management, 38, 8, 523-544.

Maruping, L. M. and Agarwal, R. (2004) Managing Team Interpersonal Processes Through Technology: A TaskTechnology Fit Perspective. Journal of Applied Psychology, 89, 6, 975-990.

Maznevski M. L., and Chudoba K. M. (2000) Bridging Space over Time: Global Virtual Team Dynamics and Effectiveness. Organization Science, 11, 5, 473-492.

Meyerson, D., Weick, K.E. and Kramer, M.R. (1996) Swift trust and temporary groups, In Kramer, M.R., Tyler, T.R., "Trust in organisations, Frontiers of theory and research", Sage Publications, Thousand Oaks, pp. 166-195.

Miles, M. B. and Huberman, A. M. (1994). Qualitative data analysis: An expanded sourcebook. Thousand Oaks: Sage.

Montoya-Weiss, M. M., Massey, M. P., and Song, M. (2001) Getting it Together: Temporal Coordination and Conflict Management in Global Virtual Teams. Academy of Management Journal, 24, 6, 1251-1262.

Northouse, P. G. (2001) Leadership: Theory and practice. Thousand Oaks, CA: Sage.

Paul, S., Sheetharaman, P., Samarah, I. and Mykytyn, P.P. (2004) Impact of heterogeneity and collaborative conflict management style on the performance of synchronous global virtual teams. Information \& Management, 41, 303-321.

Piccoli, G. Ives, B. (2003) Trust and the Unintended Effects of Behavior Control in Virtual Teams. MIS Quarterly, 
27, 3, 365-395.

Piccoli, G., Powell, A., and Ives, B. (2004) Virtual Teams: Team Control Structure, Work Processes, and Team Effectiveness. Information Technology \& People, 17, 356-379.

Poltrock, S.E. and Engelbeck, G. (1999) Requirements for a Virtual Collocation Environment. Information and Software Technology, 41, 331-339.

Potter, R.E. and Balthazard, P.A. (2002) Understanding Human Interaction and Performance in the Virtual Teams. Journal of Information Technology Theory and Application, 4, 1, 1-23.

Purvanova, R.K. and Bono, J.E. (2009) Transformational leadership in context: Face-to-face and virtual teams. The Leadership Quarterly, 20, 343-357.

Sarker, S. and Sahay, S. (2004) Implication of space and time for distributed work: an interpretive study of USNorwegian systems development teams. European Journal of Information Systems, 12, 3-20.

Schweitzer, L. and Duxbury, L. (2010) Conceptualizing and measuring the virtuality of teams. Information Systems Journal, 20, 3, 267-295.

Shipley D. and Egan C. (1992) Power, Conflict and Co-operation in Brewer-Tenant Distribution Channels. International Journal of Service Industry Management, 3, 4, 44-63.

Stark, E.M. and Bierly III, P.E. (2009) An analysis of predictors of team satisfaction in product development teams with differing levels of virtualness. $R \& D$ Management, 39, 5, 461-472.

Sudweeks, F., Simoff, S.J. (2005) Leading conversations: communication behaviours of emergent leaders in virtual teams. Proceedings of the $38^{\text {th }}$ Hawaii International Conference on System Science.

Townsend, A.M., DeMarie, M.S. and Hendrikson, R.A. (1996) Are you ready for virtual teams? HR Magazine, 41, 9, 122-126.

Uhl-Bien. M. (2006) Relational Leadership Theory: Exploring the social processes of leadership and organizing. The Leadership Quarterly, 17, 654-676.

Walter, J.B. (1995) Relationship Aspects of Computer-mediated Communication: Experimental Observations over Time. Organization Science, 6, 2, 186-203.

Yoo, Y. and Alavi, M. (2004) Emergent leadership in virtual teams: what do emergent leaders do? Information and Organization, 14, 27-58.

Zigurs, I. (2003) Leadership in virtual teams: Oxymoron or opportunity. Organizational Dynamics, 31, 4, 339-351. 


\section{NOTES}

